\title{
The Changing Politics of Foreign Policy
}

\author{
HILL, Christopher.
}

(2003). The changing politics of foreing policy.

Londres: Palgrave Macmillan. 376 p. ISBN 978-03-3375-423-8.

Christopher Hill é professor de Relações Internacionais na Universidade de Cambrigde, onde também é diretor do Centre of Internacional Studies. Hill já lecionou em outra instituição de prestígio, a London School of Economics. Seus estudos na área de relações internacionais estão focados especialmente na análise de política externa e nos estudos da política internacional europeia.

Seu livro Changing Politics é uma obra de caráter enciclopédico a respeito dos fundamentos teóricos de um campo específico da grande área de estudos internacionais conhecida como "análise de política externa”. O texto aponta a importância atual desse campo de estudos em momento de grandes transformações nas relações internacionais.

O fim da Guerra Fria, a internacionalização da vida cotidiana, a ascensão de um pretenso consenso liberal ao redor da democracia e da interdependência econômica (simbolizados no vago conceito de "globalização") induziam a acreditar em um mundo onde as fronteiras entre o interno e o externo estariam se dissolvendo, e a capacidade do Estado nacional em agir autonomamente no sistema internacional estaria sendo cada vez mais minada. Contribuiriam para isso a maior participação de atores transnacionais não estatais na vida política internacional, como instituições religiosas, grupos terroristas, um amplo espectro de ONGs temáticas (pobreza, direitos humanos, meio ambiente...), além da grande inovação que foi a doutrina de intervenção humanitária (criando exceções nas noções de soberania e autoafirmação dos povos e permitindo a ação de Estados na vida interna de outros Estados), que reforçariam a ideia de que a primazia do Estado nas relações internacionais estaria com os dias contados.

Hill aponta a tendência das análises sobre o sistema internacional em valorizar percepções sistêmicas, estruturais, com grande incapacidade de perceber e definir algum poder de agência - a capacidade das unidades da estrutura de interferir nessa mesma estrutura, ou ir de encontro às tendências produzidas por ela. Essas leituras de âmbito sistêmico nitidamente desvalorizam a capacidade dos estudos de análise de política externa de explicar e prever fatos do sistema internacional. Afinal, para elas, o que importaria nas relações internacionais seriam os constrangimentos externos. O autor aponta que essa leitura do cenário internacional e de 
suas consequências na ação política dos Estados é demasiado simplificada e defende que os Estados ainda detêm poder de "agência" no sistema internacional. Ainda seriam válidos e necessários os estudos de política externa, mesmo que Hill não negue que o cenário atual demande repensar os meios de se entender as ações dos Estados no mundo. Aponta que não importa o tamanho ou fraqueza de um Estado, sua política externa é capaz de "fazer a diferença", ainda que se devam levar em consideração constrangimentos internos e externos. Para o autor, tanto realistas quanto globalistas liberais subestimaram tal capacidade, com suas respectivas ênfases em força militar e integração de mercado.

Defendendo a capacidade cognitiva dos estudos de política externa, Hill define o que seria o conceito: política externa seria o conjunto das relações oficiais externas conduzidas por um ator independente (normalmente um Estado) nas relações internacionais (p. 3). A possibilidade de que outros atores, além dos Estados nacionais, realizem política externa é especificamente pensada para o caso da União Europeia; o grupo conta com um representante específico para suas relações externas, definido como "Alto Representante da União para os Negócios Estrangeiros e a Política de Segurança”.

Na defesa da legitimidade das análises de política externa, Hill busca o lócus acadêmico de tal campo de estudo, apontando em especial os espaços em que tais pesquisas não são nem de longe prioritárias, como nos enfoques realistas (mais especialmente neorrealistas, como em Kenneth Waltz). Tais interpretações teriam a percepção de que o sistema internacional seria dominante em certos aspectos-chave, entendendo a política externa e o interesse na política doméstica e no processo de tomada de decisão como não relevantes. Hill aponta que o viés determinista do pensamento neorrealista iria contra pressupostos da análise de política externa e sua tendência a valorizar o livre jogo dos múltiplos fatores, tanto domésticos como internacionais. Outra abordagem incompatível para pensar a política externa seria a da "escolha racional" e do "ator racional", com sua percepção da ação racional de um ator unitário com objetivos dados (no geral, a maximização do poder). Para os estudos de política externa, nada mais estranho do que negar a pluralidade das possibilidades das intenções dos atores.

Hill defende a importância dos estudos de política externa e acredita que, por sua natureza, eles devam se dar de maneira aberta, comparativa, conceitual, interdisciplinar, capaz de articular as fronteiras domésticas e externas, sem pretensão de produzir uma única teoria da política externa uniforme e abrangente. Sua importância seria ainda maior nos dias atuais, 
uma vez que as grandes alterações que o sistema internacional vem sofrendo desde os anos 1990 colocam mais dificuldades para se compreender a relação entre o interno e o externo na política dos Estados. Apesar de a política externa ser atualmente uma área mais complexa e mais contestada, ela está longe de ser insignificante e de desaparecer.

Hill enumera os desafios a que a disciplina está sendo confrontada atualmente, como a dificuldade crescente em distinguir os âmbitos interno e externo e a complexidade de analisar as novas questões normativas que se colocam para os Estados. O maior dos desafios, porém, seria a dúvida se a política externa ainda deteria o poder de agência no sistema internacional.

Ao longo de seu texto, o autor realiza um panorama da teoria que cerca os estudos de política externa, além de apontar suas interpretações para conceitos relacionados a esse tipo de pesquisa. Seu texto, dividido em três partes, se inicia com o debate a respeito do poder de agência nas relações internacionais, como as ações são geradas e conduzidas no cenário internacional e por quem. Na análise de política externa, esse tipo de preocupação buscaria suas respostas não em entidades abstratas, mas nos tomadores de decisão, os responsáveis oficiais pelas ações dos Estados no sistema internacional. Nesta seção, o autor aborda os principais poderes desses atores, assim como as dificuldades de se analisar seus atos a partir das teorias do ator racional e da escolha racional.

A segunda parte analisa o contexto internacional (a estrutura) em que as ações são realizadas. Hill aponta os constrangimentos que podem ocorrer para a ação dos Estados, mas também os espaços que se abrem para ações autônomas. Nesta parte, indica a redução do poder explicativo do cenário internacional presente na geografia, em especial nos estudos mais deterministas de enfoque geopolítico. Para o autor, valorizar a capacidade de ação dos Estados não coaduna com entendimentos estruturalistas das relações internacionais, ainda que não negue que, no geral, os tomadores de decisão tenham uma visão das relações internacionais como um sistema, com padrões regulares de interação, e que o ambiente externo permaneça sendo central para qualquer política externa (p. 164).

Sua proposta de análise de política externa tem o mérito de, ao mesmo tempo em que defende a existência deste campo específico, demandar sua articulação com outras maneiras de se pensar a vida política nacional e internacional. Nega qualquer pretensão de pensar as relações internacionais em separado da vida cotidiana doméstica, reforçando a característica positiva da subdisciplina em conseguir apontar como o ambiente interno é um dos formadores da estrutura internacional. $\mathrm{O}$ autor defende que todas 
as noções centrais da política moderna estão hoje implicadas com a política externa e que ela não pode ser entendida como um espaço isolado e livre de constrangimento. Essa maneira de pensar a política externa se aproxima de diversos pesquisadores - como Maria Regina Soares de Lima e Letícia Pinheiro, para citar autores brasileiros - que buscam entender a política externa dos países democráticos como uma de suas políticas públicas, aproveitando as abordagens teóricas e metodológicas desse campo para compreender os modos como as agendas são estabelecidas, como se dá o processo decisório e como medidas são implementadas.

A terceira parte do livro encaminha a discussão a respeito do que define como "transnacionalismo": o surgimento de novos atores transnacionais e o questionamento a respeito da dissolução da comunidade específica a que o Estado presta conta. Hill aponta como questões morais vêm colocando novos desafios para os países, fazendo com que surjam novas constituencies, desta vez externas, às quais podem ter que se reportar.

A parte mais interessante de seu livro está na divisão da análise da política externa por três chaves: a ação, a escolha e a responsabilidade. A ação se refere à capacidade de existirem atores e eles serem relevantes no sistema internacional. Não importa o tamanho ou a fraqueza de um Estado, ele sempre será capaz de fazer a diferença, ainda que sob constrangimentos que podem ser realmente grandes. A própria ideia de uma política externa indicaria a capacidade de alguma liberdade. Estado sem um mínimo de autonomia não possui política externa, e todo Estado tem de alguma forma política externa. Hill antevê o surgimento de políticas externas feitas por entidades subnacionais. Cita os exemplos tímidos de países federativos que permitem que seus estados possam ter autonomia em assuntos de low politics, como turismo, e aponta que a constatação desses exemplos pode indicar a necessidade de se repensar como um imperativo vital de um Estado a manutenção do monopólio sobre sua política externa, seguindo preceitos hobbesianos.

Hill também aponta como o poder de agência nas relações internacionais vem ganhando ainda mais complexidade com a participação cada vez mais importante de atores transnacionais, tema de seu capítulo 8. O autor mostra como, de atores tão diversos como ONGs ambientalistas e grupos terroristas, novos constrangimentos são feitos à ação estatal, principalmente por influenciarem a constituency interna, sua própria população.

A ideia de escolha indica as dificuldades encontradas pelos tomadores de decisão para agir, pela constatação natural de que existiria mais de uma opção de ação. Como o entendimento da análise de política externa 
percebe a natureza e as fontes das preferências como determinantes não preestabelecidos, a escolha se torna um elemento de alta complexidade. Hill ainda chama a atenção para o fato de que na área de política externa são ainda mais nítidas as diferenças entre escolhas e seus resultados, com graus nem sempre seguros de previsibilidade das ações.

Além disso, ressalta que nem sempre se poderia apontar a política externa dos Estados como uma variável dependente. Ela pode, em alguns momentos, ser capaz de realizar iniciativas e de fazer alterações significativas nos sistemas internacional e doméstico. Essa relação dialética, Hill a define como "structurationism" (neologismo que poderia vagamente ser traduzido por "estruturacionismo"), mistura entre "estrutura" e "atores", em que estruturas moldam atores e atores fazem estruturas.

\section{Ética e Política Externa}

A responsabilidade faria referência à nova maneira de perceber a dimensão ética das relações externas dos Estados. Hill é um entusiasta da importância de se pensar a relação entre ética e relações internacionais, algo não muito comum entre teóricos das RI. Para o autor, na política externa de qualquer país, a prática e a ética convergem inexoravelmente (p. 297).

Nas relações internacionais, a responsabilidade estaria expressamente vinculada às obrigações dos Estados com suas populações, mas também com o próprio sistema internacional, em temas como a expansão do mundo livre, a redução do flagelo da pobreza, de dívidas externas etc. Além disso, tomadores de decisão de países democráticos poderiam estar conectados com uma vasta gama de constituencies fora de seu território, como a opinião pública internacional, partidos políticos afins etc.

Hill aponta que os tomadores de decisão estão propensos a ter algum grau de responsabilidade e compromisso com sua própria consciência, sua história pessoal e mesmo com o conjunto da humanidade (p. 298). O passar dos tempos teria mostrado que o que era consenso no passado hoje não seria mais adequado: o estadista não pode mais ser responsável somente por seus concidadãos. Ainda assim, não ignora que a prioridade dos Estados serão sempre suas populações.

A responsabilidade nas relações internacionais teria três dimensões. Ponto fundamental para os tomadores de decisão seria a legitimidade junto à população de seu país e, cada vez mais, seria importante pensar a necessidade de legitimar suas ações e garantir reconhecimento por elas junto a sujeitos externos. Legitimidade interna e externa garantiria ao 
Estado exercer suas responsabilidades internacionais. Tal caráter indicaria que o Estado é o único agente das relações internacionais a quem seriamente conseguiríamos criar exigências e acompanhar seus atos (to account). A capacidade de exercer responsabilidade seria facilitada pela segunda dimensão, a identidade: o sentimento de compartilhar uma mesma cidadania entre toda a humanidade. A identidade precisaria estar presente em ações internacionais de responsabilidade para que não sejam consideradas personalistas e não confiáveis. $O$ terceiro ponto, a dimensão ética, seria o mais complexo e debatido dos três. Hill defende que toda política externa acompanha preceitos éticos, além de ser um dos agentes por excelência do cenário internacional a agir por determinações morais. Apesar de considerar esse um fator importante nas relações internacionais, Hill é pragmático ao afirmar que não é possível para uma política externa ser completamente cosmopolita em sua ética, isso é, dedicar-se por completo a uma possível comunidade internacional e agir como se toda a humanidade vivesse sob os mesmos valores e direitos. Afinal, a política externa seria constrangida por seus outros interesses particulares, não necessariamente ligados à dimensão moral.

Hill é otimista a respeito da possibilidade do compartilhamento de valores por toda a humanidade, ainda que não sejam muitos. Indica os lados positivos do comprometimento dos tomadores de decisão em política externa com outros grupos além de sua população. Uma leitura parcialmente inocente, por não destacar as dificuldades inerentes à relação entre política externa e moralidade, em que poderia ser questionada a existência de valores verdadeiramente universais, ou a capacidade de definir quando os atores agem sob interesse ético ou se utilizam dessa dimensão como mera legitimadora de posturas movidas por outros interesses.

Magno Klein*

\section{Recebida em}

outubro de 2015

\section{Aprovada em}

fevereiro de 2016

\footnotetext{
* Magno Klein é Mestre em História Comparada pela Universidade Federal do Rio de Janeiro (UFRJ); Doutor em Ciência Política pelo Instituto de Estudos Sociais e Políticos (IESP) da Universidade do Estado do Rio de Janeiro (UERJ); pesquisador associado ao Laboratório de Análise Política Mundial (IESP - UERJ); e editor da revista Cadernos de Estudos Sociais e Políticos. magnoklein@gmail.com.
} 